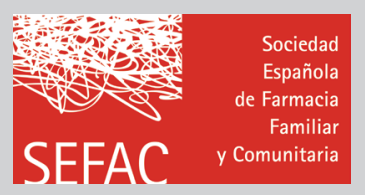

\title{
Expandiendo la farmacia asistencial
}

\section{Marián Aparicio Cercós}

Vocal de Relaciones Institucionales de SEFAC.

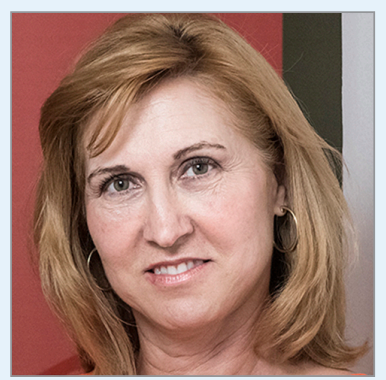

Marián Aparicio Cercós

\section{PALABRAS CLAVE}

Farmacia asistencial, servicios profesionales farmacéuticos asistenciales

\section{KEYWORDS}

\section{Pharmacy,}

professional services healthcare pharmaceuticals
Entre los valores de la Sociedad Española de Farmacia Familiar y Comunitaria (SEFAC) como sociedad científica se encuentran la innovación, la cooperación y el liderazgo. Tres aspectos esenciales para avanzar en el desarrollo de la farmacia asistencial y la implementación de los servicios profesionales farmacéuticos en beneficio del paciente. SEFAC lleva años trabajando en esa dirección, colaborando con otros agentes del sector y distintos interlocutores para que esa farmacia centrada en la provisión de servicios asistenciales sea una realidad firme y consolidada. Sociedades científicas, colegios oficiales de farmacéuticos, asociaciones de pacientes, partidos políticos, etc. han sido testigos de este trabajo que ha cristalizado en numerosas iniciativas y proyectos y que tuvo uno de sus puntos culminantes más recientes en el VIII Congreso Nacional de Farmacéuticos Comunitarios, que nuestra Sociedad celebró con un sobresaliente éxito el pasado mes de mayo en Alicante, con la asistencia de más de 1.500 profesionales del sector.

Conviene llamar la atención sobre este hecho, no solo porque se volvieran a superar las cifras de ediciones anteriores, sino porque también hubo un gran crecimiento en las comunicaciones presentadas, con más de 400 (un 35\% más que en 2016) procedentes de más de 1.000 autores, lo que da cuenta del compromiso y el interés creciente de los farmacéuticos comunitarios por la investigación en farmacia asistencial y sus respectivos servicios.

Las conclusiones del congreso también sirvieron para evidenciar el avance que está teniendo la farmacia asistencial promovida por SEFAC y el liderazgo que se está llevando a cabo. Se defendió el derecho de los pacientes en el domicilio a beneficiarse de los servicios profesionales asistenciales (SPFA) mediante un adecuado desarrollo de la Atención Farmacéutica Domiciliaria (AFD). También se llamó la atención sobre el importante rol que puede desempeñar el farmacéutico comunitario en materia de salud pública, tanto en desarrollo de servicios concretos en la materia (como la cesación tabáquica o la medida de la presión arterial) como siendo un agente activo en salud en el marco de las estrategias de las distintas administraciones. Asimismo, se puso de manifiesto nuestra labor en la lucha contra las resistencias a los antibióticos, gracias a la colaboración activa que en los últimos años venimos manteniendo con la Agencia Española de Medicamentos y Productos Sanitarios (AEMPS) y se trabajó para mejorar la coordinación entre niveles asistenciales y con otros profesionales sanitarios en materias como la adherencia terapéutica, la indicación farmacéutica, los sistemas personalizados de dosificación o reacondicionamiento (SPD) y la atención a las personas con patologías crónicas.

Las conclusiones integras puedes consultarse aquí.

\section{Más allá de nuestras fronteras}

Pero el congreso también fue más allá e impulsó más que nunca su vertiente internacional, no sólo por la presencia de ponentes internacionales en distintas partes del programa, sino por profundizar en el conocimiento de los modelos de otros países en la provisión de los SPFA (Francia, Portugal, Escocia). También es importante destacar la asistencia de representantes de países iberoamericanos, con un objetivo claro: aprender de la experiencia española en la farmacia asistencial y estrechar los lazos colaborativos para fomentar la práctica farmacéutica, la investigación y la formación de calidad para los farmacéuticos comunitarios.

Fruto de este trabajo es la expansión que más allá de nuestras fronteras viene haciendo SEFAC en los últimos años, primero con la firma de un acuerdo de colaboración en 2015 con la Ordem de los Farmacéuticos de Portugal en materia de SPFA y, un año después, por nuestra incorporación a la Red Europea de Atención 
Farmacéutica (Pharmaceutical Care Network Europe), que tuvo su primera reunión en España a principios de año en Fuengirola (Málaga).

Esta expansión se ha concretado también con la presencia en otros foros internacionales, como el reciente congreso de la Federación Internacional de Farmacia (FIP), celebrado en Escocia y donde hemos llevado los resultados de distintos trabajos. También en las conversaciones que desde mayo venimos manteniendo con el Foro Farmacéutico de las Américas, que estuvo presente en nuestro congreso a través de su vicepresidenta, la farmacéutica argentina Laura Raccagni. Pero, además ese interés internacional, no solo por parte de SEFAC, sino del resto de agentes que reconocen nuestra posición puntera, también se vio confirmado por la participación de nuestro presidente, Jesús C. Gómez, en el III Simposio Centroamericano y del Caribe de Actualización en Atención Farmacéutica, celebrado en Costa Rica los pasados 23 y 24 de agosto.

El presidente de SEFAC impartió, con una gran acogida, tres conferencias en las que aportaba las líneas de trabajo de SEFAC en cómo adaptar la farmacia a las necesidades y expectativas de los pacientes (en el que, entre otras cosas, desglosó las conclusiones del estudio Refcom. La realidad de la farmacia comunitaria en España); cómo se estaban desarrollando los SPFA en la farmacia comunitaria española (tanto con conceptos generales como con casos prácticos a través de servicios como la revisión del uso de los medicamentos o la cesación tabáquica) y, por último, la comunicación entre niveles asistenciales a través también de distintos ejemplos prácticos, en este caso a través del programa impacHta, para la prestación de los servicios de medida y control de la presión arterial y cálculo del riesgo cardiovascular.

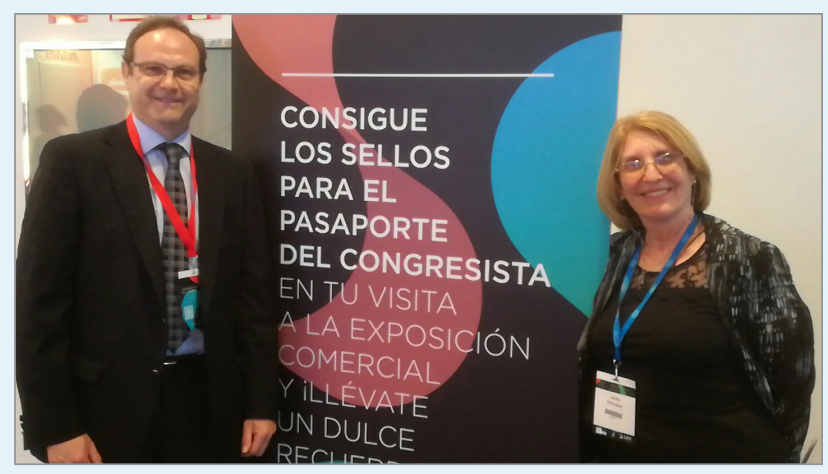

Sin duda la participación en este tipo de eventos sirve también para dimensionar la actividad de SEFAC a unos niveles más destacados institucionalmente, generando nuevos contactos y sinergias y le permite difundir no solo su labor como sociedad científica, sino el valor de la farmacia asistencial que se viene desarrollando desde hace años en España.

Y es que SEFAC tiene claro que el impulso de la farmacia asistencial no es una cuestión exclusivamente local. Es necesario que esta corriente se asiente también en otras latitudes para que la profesión se refuerce y perviva como garante del uso adecuado de los medicamentos ante la población. Llevamos tiempo trabajando, como lo demuestran las más de veinte carpas de SPFA que han recorrido la geografía española en los últimos años, para que los ciudadanos conozcan y valoren el potencial sanitario de nuestra profesión. SEFAC seguirá trabajando en ello, dentro y fuera de España, para que este modelo siga siendo un referente dentro y fuera de nuestras fronteras.

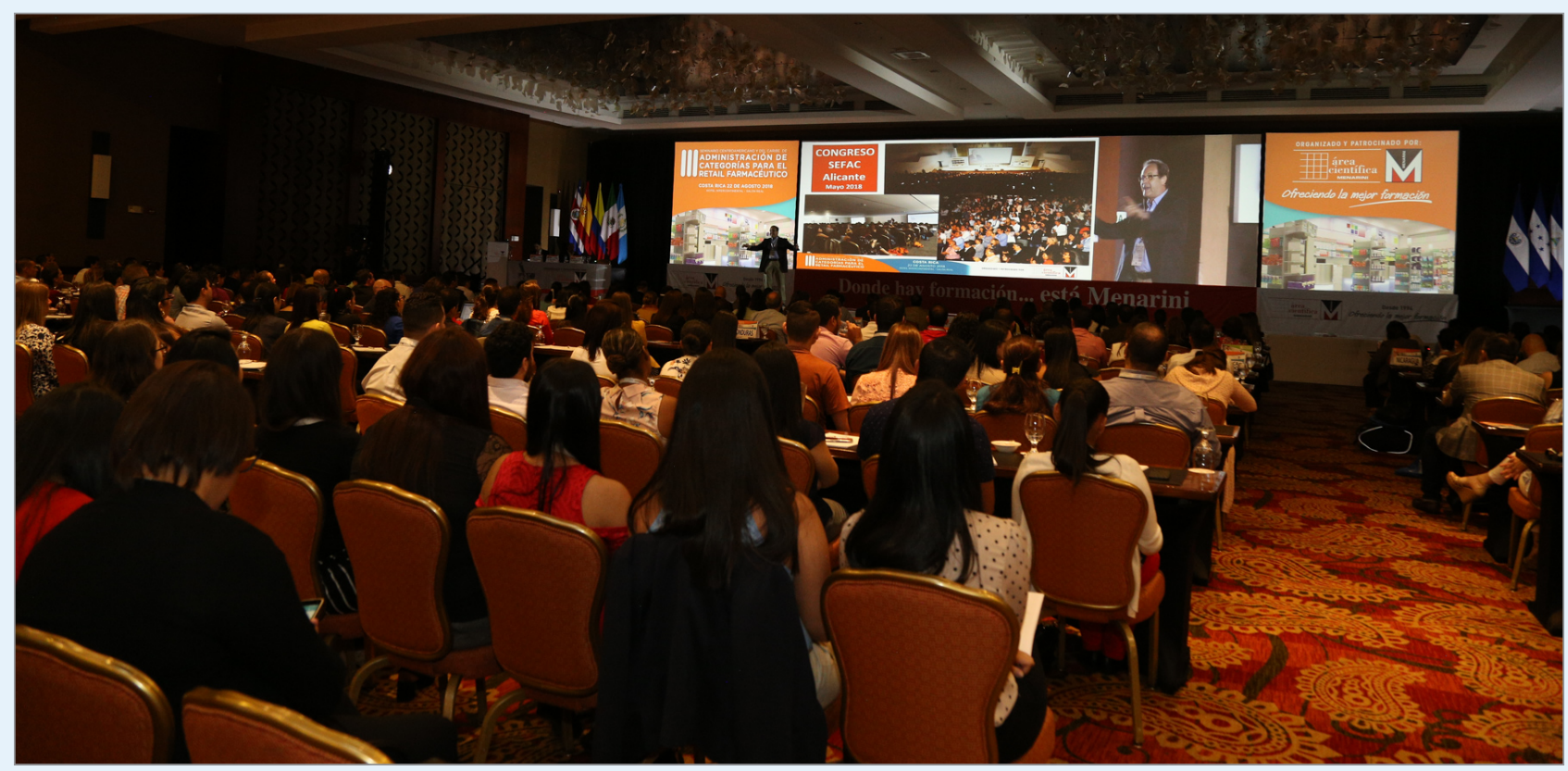

